Jean Crocker* \& Philip Shaw*

\title{
Research student and supervisor evaluation of intertextuality practices
}

\begin{abstract}
Intertextuality is essential in academic writing but it is governed by quite complex conventions. Different intertextuality practices can be judged evidence of academic competence or incompetence, or condemned as plagiarism. Learners can break the conventions with criminal intent, or from ignorance, or because their language proficiency prevents them from doing anything else. This paper reports the results of interviews with academic staff in a British university and their postgraduate students about intertextuality practices. The interviewees ahowed a wide range of - sometimes contradictory - attitudes to quotation, referencing, and copying. Several pointed out the developmental advantages of various types of copying.
\end{abstract}

\section{Introduction}

Academic writing makes extensive use of intertextuality, but regulates this use rather tightly. Infringements of the rules, if observed, can be punished as plagiarism, and fairly frequently are so. Nevertheless, such infringements are very frequent, are often not observed, and can be rewarding. For example, Currie (1998) describes the experience of a Cantonese-speaking student in a Canadian university who saved herself from failing by developing a skilful and arduous procedure of copying appropriate sections verbatim from the textbooks. She did this after finding that her own work was not acceptable. This subject's concern was survival rather than education, but Spack (1995) describes a Japanese student in a US university who was anxious to make full use of the educational opportunities and hence normally aimed at full compliance with the process intended in each assignment. On the one occasion when, under pressure of time, she copied large sections from a textbook she was not discovered, indeed rewarded by good grades.

$\begin{array}{lll}* \text { Jean Crocker } & * & \text { Philip Shaw } \\ \text { Centre for Lifelong Learning } & \text { Department of English } \\ \text { University of Newcastle } & & \text { University of Stockholm } \\ \text { Newcastle upon Tyne NE1 7RU, UK } & & \text { S-106 } 91 \text { Stockholm }\end{array}$

Hermes, Journal of Linguistics no. 28-2002 


\section{0}

Student willingness to make use of illicit intertextuality - plagiarism may result from a variety of factors. In this volume Mayumi and LoCastro show that lack of training, itself perhaps derived from culturally different attitudes, is probably important. The examples from Currie and Spack show that the practice may also be a rational strategy to meet the excessive demands of a course. Since the demands are very likely to be excessive when one is studying in a foreign language in competition with monolingual speakers of that language, plagiarism may be found in this environment whatever the cultural background. Sherman (1992) reported that her Italian students copied a great deal when writing in English. However, plagiarism is also very common among Western students studying in their mother tongue, in Scandinavia as well as in other regions (Vertex 2000). Ryan (1998) found that seven out of 42 US information-technology students 'plagiarised most or all of their papers'. When challenged, they claimed ignorance despite rather intensive information programmes about the problem. In their case, it is hard to see the cause of this behaviour as other than a desire to get the marks without going through the process.

It is clear from the literature (Scollon 1994,1995, Pennycook 1996, Howard 1995ab) that the category 'plagiarism' is a complicated social construct bound to a particular location (our time) and place (our culture). Many writers present it as rather old-fashioned - modernist rather than post-modern (Warner 2001), or sexist rather than feminist (Howard 1995b), but most seem to agree that it has a very specific historical and cultural origin. It is also clear that academic intertextuality practices are remarkably complicated. Ignoring for the moment legitimacy and effectiveness, the focus of our survey reported below, intertextuality varies on three dimensions: quantity, closeness of the wording to the source and documentation. In terms of quantity, one can use sources extensively or sporadically, or only draw key items strategically from the sources. One can paraphrase the source (more or less effectively, as we will see below), or copy word-for-word. Between these two there is the possibility of 'near-copying' (Campbell 1990), that is partially rewording a text, retaining its structure, rather than paraphrasing or summarising it. If copying is done, it can be done in large or small chunks. Howard (1995) uses the term 'patchwriting' for a practice which interweaves sentences copied directly from one or more sources with original writing (and this is what Currie's subject mentioned above did, because she could not paraphrase). 
Finally copying can be done with or without quotation marks (that is documentation of the fact that one is quoting word-for-word) and with or without documenting sources.

The student has to learn which of these practices the academic culture approves and which it condemns, and previous experience in the education system may not be very helpful. The university normally rewards the use of sources, where the school may have encouraged thinking for oneself. Schools do not (or used not to) necessarily teach referencing practices. The problem might be worse in some cultures than in others; as LoCastro and Mayumi show in this volume, the demands of (international? Western?) academic conventions may be very unexpected in Japan.

Nevertheless, although the great emphasis laid in recent writing on the cultural specificity of plagiarism might suggest that the activity covered by the term would be affected by cultural factors, there is rather little evidence of this. Dong (1996:452) 'detected little in the way of confrontation between these students' native language and culture and their acquisition of academic language and conventions' in his study of Chinesespeaking students learning intertextuality strategies in the US. Practices describable as plagiarism are apparently frequent among all groups of students, irrespective of culture or mother tongue.

Part of the explanation for the survival of these practices in the face of clear and frequent denunciation is that intertextuality practices are complicated and some are rewarded and others condemned. Another part might be found in the fact that, as the references above show, plagiarism often goes unpunished. The students may have the feeling that the institution is speaking with a forked tongue. Most writing presupposes that plagiarism is uniformly condemned within Western academic culture, as a consequence of our whole attitude to ownership of knowledge. This assumption is natural enough if one trusts official statements. Pecorari (2001) for example looked at plagiarism regulations in more than fifty universities in Britain, the US, and Australia. She found that they all defined plagiarism in similar terms, and condemned it categorically 1.

1 Sometimes the terms of the definition were so similar that Pecorari suspected they had plagiarised from on another! Moreover, Pennycook 1996 and Standler 2000 give different documented examples of plagiarism of anti-plagiarism wording. 
Thus one UK university's statement on academic conduct observes 'Passages copied verbatim from the work of another must be enclosed in quotation marks. A full reference to the original source must be provided. The substitution of a few words in an otherwise verbatim passage will not obviate the need to use quotation marks and to provide a full reference' (University of Newcastle upon Tyne). This is probably a standard prescription.

It is clear from reading students' academic work that they do substitute 'a few words in an otherwise verbatim passage' without using quotation marks, and it is clear from the literature that the 'rules' as to plagiarism are frequently broken, whether from ignorance or deliberately. One could add that, like conversational maxims (Grice 1975 ), academic conventions of this kind can be flouted as well as broken (Greenall forthcoming). Richards and Skelton (1991) give several examples of successful unreferenced allusion to the common culture of writer and reader. In the most striking a graduate student writes in an essay 'This work is neither the heart of the matter nor the end of the affair' alluding to the title of an article (Swales 1985) which itself alludes to the titles of two novels by Graham Greene. This kind of unreferenced intertextuality aims to be recognised, presupposing that the work alluded to is common knowledge.

For students writing dissertations, intertextuality is one of the many things that are negotiated between the supervisor and the student, as part of a fairly long-term relationship during which the student is gradually inducted into the community of practice (Prior). It is useful to be reminded that plagiarism is a construct, and that it is frequent, but we also need thick descriptions of what is going on in that induction, which will enable us to see how, or whether, plagiarism fits into it.

An investigation of the actual practices within the culture can rest on and make use of a range of situated descriptions of the induction of research students into the community of practice (Prior, Cadman). These are studies which seek 'to understand the ways particular people within particular relationships learn to engage in the diverse practices of a particular discipline' (Prior 1995a, 295). Prior talks about 'how students, instructors and communities themselves are being formed and re-formed through writing, response, and revision' (Prior 1995a, 294). The disciplinary enculturation process is a dialogue between the supervisor and students and a particular draft is an item in that dialogue. Each draft sends a 
particular set of messages and invites a particular set of responses. So the question is what kind of message a particular kind of intertextuality sends and what response it invites.

\section{Aim}

This paper aims to start to provide an answer to this question. More specifically, it asks what attitudes to intertextuality in student writing are manifested in practice among research students and their supervisors in a British university. Which types of intertextuality are condemned, which are condoned, and which are rewarded? The paper aims to reconceptualise 'Western attitudes to plagiarism' in terms of the actual research writing process and the complex negotiations involved in producing a dissertation with a supervisor. Further, it aims to set these attitudes in the context of disciplinary culture.

\section{Method}

We interviewed staff members and overseas research students from a variety of disciplines at Newcastle University. A total of fifteen students and eleven staff members were interviewed separately (staff by Shaw, students by Crocker), including eight cases where the interviewed staff member was the supervisor of the interviewed student. The departments surveyed were: Agricultural Economics, Politics, Development Architecture, Business Management, (regarded as social sciences) Computing, Marine Engineering, Mechanical Engineering, Organic Geochemistry, (technology) Law, and English Literature ('others'). Students interviewed came from Bangladesh, China, Germany, Indonesia, Korea, and Pakistan.

Staff were chosen because they had overseas research students, and most also had British students. All were supervising either Masters' dissertations or $\mathrm{PhDs}$ or both. Students were then chosen as far as possible from among those they were supervising.

Interviews with staff lasted for about half an hour; with students they were often longer. The format was a free discussion of plagiarism and its problems, followed by ten predetermined questions, in so far as they had not been answered in the free discussion. The interview with students also made use of work which students had recently written in their departments. In each student's work, three passages were identified which 


\section{4}

according to the intuitions of the EAP lecturer (cf LoCastro and Mayumi, this volume) might be copied from a source. Then the students were interviewed and asked why they had chosen words and whether they had a source.

Analysis consisted of simply reading through the transcripts and notes repeatedly, trying to find common features in what they said (cf. Berkenkotter and Huckin 1995, 102). Particular attention was paid to apparent contradictions within and between transcripts, which seemed likely to reveal key issues.

\section{Results}

\subsection{Disciplinary difference}

There was a good deal of similarity among the accounts that supervisors in different disciplines gave, and that is our focus here. But there were also disciplinary differences. For example it seems that for some technologists copying words is less of a problem, so long as empirical work is adequate:

1 if they're laying down the basic theory then there's no other way you can do it, you might as well copy it out of a textbook as do anything else

$2 \quad$.... So you do get that, but of course also you get them just taking word-for-word from references which you're familiar with yourself and I think, as I say, most of the staff here condone a small element but clearly not a lot, the odd sort of half a page here and there but not huge chunks

Correspondingly, the social sciences and humanities seem to be more inclined to prosecute plagiarism through the disciplinary system. Actual prosecutions for plagiarism were mentioned in law, architecture, literature, and business but none in the technological subjects.

There was a similar pattern for the students. The Politics, Architecture and Computing students were most sure that the source text should not be used without quotation marks, whether with reference or not, while an Engineering postgraduate shared the views of the Engineering supervisors, in that it was 'OK if it's common knowledge or in several books' although he thought no more than two sentences should be used like this. 
Legitimate (referenced, in quotation marks) word-for-word quotation of secondary material may be more acceptable in some disciplines than in others: A technology lecturer said 'we don 't use quotes a lot in science' where a lawyer said

3 if someone is seeking to give a critical appraisal of another person's view I would expect that view or the kernel of it to be distilled in a quotation

The students' views coincided, in that an Engineering student said that quotations were 'not used in structural topics' though 'sometimes used in environmental engineering', while in contrast the Business Management student thought one could quote a lot, and the Architecture student thought several times a page.

These points reflect the fact that language and hence particular formulations are more constitutive for social sciences and humanities. In the technological subjects the mathematics provides a different means of communicating and establishing an identity.

\subsection{Conflicting evaluations}

The rest of the results reported here are focused on four apparent contradictions or disagreements in our data: whether plagiarism is easy to recognise or not, whether it is a crime or a developmental phase, whether it is bad because it is cheating or because it is rhetorically ineffective, and the paradox that quotation is legitimate but shouldn't be used. These enable us to develop a model, presented in the Discussion section.

\subsubsection{Plagiarism is hard to detect $O R$ is obvious}

Many of our sources claimed that copying was hard to detect or gave examples of it being overlooked or identified by chance: A social scientist said: 'if you don't know the sources it's difficult to know whether it has been the person's work in question that was regurgitated' In fact it seems possible that this difficulty has entered folklore. One version of a story which recurred three times in eleven interviews - could it be an urban myth, a Wandersaga, or is plagiarism really so frequent? went:

4 ..some gross and obvious cases, for example a classic that we've had the external examiner recognises his own work which internal examiner 
has not recognised and gives it a beta and the external says, well I thought it was rather better than that when I wrote it in nineteen fifty... We have had that, rather embarassing.

On the other hand, copying was also represented as easy to detect and basically a stage one has to go through (called 'patchwriting' by Howard 1995). One technologist said:

5 Where it's pretty obvious, it's in their draft form: I write 'this is not your work, I can see it's not your work, I'm quite happy that you leave it in there but for God's sake give it a reference, you know, that's the thing to do

So there are different kinds of phenomena. Some are hard to recognise and picked up late, if at all, and it is these that represent a disciplinary problem. Others are easy to recognise, picked up early, during discussions of drafts, and possibly tolerated.

Interviews with students investigated this second type of copying. In many cases it appeared that the passages were indeed copied. The architect, who had been clear that copying was unacceptable, revealed that all three were from the Internet. The Engineering postgraduate had in fact translated parts of a German textbook without giving a reference. This was partly because he didn't know how to give a reference in that situation, but he also said that if it had been an English book, he would have given a footnote because the lecturer might have read and remembered it. In both these cases short cuts were being taken which might have been picked up and then either corrected or condoned by the supervisor. These examples confirm that plagiarism can be easy to recognise, and hence picked up early in the supervision process and capable of contributing to development.

However, the Computing Science student turned out to have correctly transferred language he had learned in a different situation. He had referred to a group in favour of something as 'the for group', which appeared to the EAP lecturer to be too good not to be copied, but in fact he had taken the expression from lectures he attended where they had discussion between 'for' and 'against' groups. Deliberate use of the idioms of one's discipline is a sensible and quite frequent strategy (Leeke \& Shaw 2000), but the example underlines the difficult distinction between sensibly using the language of one's discipline and criminally committing plagiarism. One reason why plagiarism is particularly problematic for writers working 
in a foreign language is that it may not be obvious to them which phrases are distinctive and need referencing and which are the common coin of the discipline. Such writers may not recognise that a particular phrase 'ought' to be treated as a quotation.

\subsubsection{Plagiarism is a crime $O R$ plagiarism is a developmental phase}

While the university as a whole, and most departments individually, issue documents identifying plagiarism or illicit copying as a crime, many supervisors see it as merely a rather lowly stage of development. The lawyer said of research students who were native speakers of English:

6 I think in the early stages the mistake many students make is trying to write everything in their own language $[=$ words $]$ because there's an issue about research and the place of research and the conventions of using other work. People tend to get a rather generalised mass of prose, which is neither academic nor homespun, but an odd combination, that's my experience They start copying when they are forced to face up to the need to use other works in a particular way that this becomes a problem. I'm talking about a straightforward student who has no bad intent ... Obviously if one's got someone who hasn't got bona fides that's a different matter. Copied ideas start to appear two months or so in.....

This is a very clear view of copying as almost a necessary stage in academic socialisation. An even more prosaic view was put by a teacher of literature to graduate students, mostly not native speakers:

7 Shaw: If someone copies the words out of the book and gives a reference, how do you react to that?

Lecturer: one would try to pick that up early on, if they go on doing it one would keep on at them, you must, you must do this

Shaw: and eventually it becomes a serious problem?

Lecturer: Um....[no, it doesn 't, it just gets low grades]

Copying can also be viewed as acceptable, even useful, at one developmental stage but not at another. An engineering lecturer said, 'One would not expect unattributed quotation in a PhD' but that first year overseas student work is often copied from the textbook. Similarly first or second year undergraduate lab reports are a difficult genre and the reports are often incomplete. Hence it is a good thing if the reports have all the 
48

conventional parts, and it does not really matter if they are copied, especially if written by students whose mother-tongue is not English. Discussion with undergraduates confirmed that they are expected only to give their sources in a bibliography, not reference individual points.

So from the staff point of view plagiarism can be viewed and handled either as a crime, using university regulations, or as feature of a particular stage of development.

Students generally said that copying by any student, not necessarily themselves, without footnotes or references was a sign of some kind of weakness or disadvantage rather than a deliberate attempt to cheat. It could be due to lack of knowledge about how to use the literature; not realising what they had done; forgetting to give the reference (two interviewees suggested this); forgetting where they found it on the Internet; and limited English. A typical comment was 'They haven't studied hard, they're in a rush they put all their notes in without dealing with them properly'. These reasons might be regarded as developmental.

Less frequently they said that a student would copy to cheat, or to give the impression it was their work. This would be a kind of crime. However, even this could be an understandable attempt to find an effective means of counteracting a language problem. A German Politics student said:

8 They couldn't say what they want to say and found something and it sounds as if it's their own idea

and a Chinese student of English Literature said of doing this in her own work:

9 I don't want to give so many quotes and your [ $=$ my $]$ words are not quite good.

\subsubsection{Plagiarism is bad because it is against the rules: $O R$ it is bad because it is rhetorically inadequate}

Some staff interviewees described plagiarism, copying, etc. in terms of rules one must obey, conventions, etc.

10 copying is against the rules of the game ...... Whose game are you playing? (social scientist)

11 You lose lots of brownie points for not referencing (technologist) 
but others (or the same people elsewhere) also gave explanations of why it failed to perform the function intended of academic writing. These are the features like 'intelligence' and orientation to one's thesis in the writing that Cadman (1997) refers to.

12 a clearly articulated differentiation [of your work and others'] is what you get maximum benefit for [ $=$ maximum credit] (social scientist)

13 They have to demonstrate clear and succinct understanding ....A patchwork quilt of a Literature Review is no good, just stitching it all together, got to get them away from that....(social scientist).

14 You have to put previous work in the context of your own, and you can't do that by copying .- you need to report in relation......copying single lines won't get the sense of the whole work, you're not going to have the architecture to put your work into, just details...(technologist)

So again there seem to be two possible ways of judging a piece of intertextuality: legitimacy in terms of a set of rules versus effectiveness in achieving the goals of the matrix text.

Students seem to see this largely in terms of rules, often their own sets of rules, about how they use the literature. Two students said that the familiarity of an idea to themselves affected their practice. A Korean student of Computing Science used more quotations when dealing with an idea new to him (this did not necessarily mean he was plagiarising otherwise). The Chinese student of English Literature said that when an idea became part of her own thoughts she would no longer give a reference. She was surprised when the EAP lecturer commented afterwards that this could be questionable.

The German Politics student had asked her academic tutor how many sources were expected for a piece of work. In Germany, she had been told there should be a minimum of three sources for a three-page essay and ten for a five-page essay. A second German Politics student said that her lecturer in Germany had asked for three quotations or references a page. Having items in a bibliography was not enough, because

15 if it's just in the bibliography with no footnote, they don't believe you have read it.

A lecturer in England had complained that she had too many quotations in the text. So differences in academic culture may play a part in terms of rules. Intertextuality practices can be the focus of different priorities. The list of sources and references in the text shows that the students has 
read adequately, while the use made of the sources shows that the student has mastered the generic requirements of the discipline. It seems possible that this student's German teachers had been concerned to police adequate study, while the British one was more concerned with policing generic appropriacy.

There were not many other comments on intertextuality practices as features of rhetorical adequacy. A Pakistani student of Organic Geochemistry said that her supervisor had pointed out that if you don't differentiate between your work and that of others it looks like copying. This is a concern to be effective and legitimate. A Politics postgraduate thought it was effective to paraphrase without references, if you used a lot of sources, because the lecturer wouldn't know - which is a concern to be effective rather than legitimate.

\subsubsection{Quotations are legitimate BUT shouldn't be used}

We were struck in the staff transcripts by a kind of double message about quotation. This was clearest in the following pairs of comments from two social scientists:

16 the first thing that I've noted is, and I've written it in bold, some bits in capitals, If you quote a work you MUST use quotation marks and give the reference, this is serious since a failure to do so will result in your failing the degree...

BUT ....

17 if the students regard quoting as an alternative to changing it would you accept that?

No I don't think I would, I sense that it's sensible to use quotes when an impact has to be made, for something that's important or for something that's absolutely screwball and hey look so-and-so said this

18 We say to students 'look if you really think this language is spot on and really makes the point you want to make, use it, but put it in quotation marks'...

BUT

19 in terms of secondary sources I would expect there to be very little direct quotation 
Similarly the Handbook for one of the technology subjects said : 'If you copy someone else's words, make this clear - quotation marks or indented paragraphs' but the staff member interviewed said in an interview that there would ideally be no quotations in a dissertation.

A literature teacher had an interesting comment which confirmed that all students may go through a stage of quoting too much, but that linguistic proficiency makes it easier for some to progress beyond it than for others.

20 With native students you're going to say much more easily, aren't you, there's just too much reliance on quotation, what we're wanting is your command of these things, but you're using quotation to prove the point rather than to open the point. Now ultimately you have the same end in view with the overseas students, but I think you can't, you would be much more tolerant I think of an essay that was made up of a lot of quotations sort of moving through the subject because you're sort of aware that if they did the opposite and sort of started being creative all over the place they're liable to make the most terrific mistakes. things of that kind so you're sort of saying if they are over-reliant on quotation of secondary reading, it's difficult to see this as an immediate fault because they're actually going through the stuff and learning, you're probably trying to gently sort of say to them that's terrific, you're getting some sort of feel about this now, what about some sort of explanation of the relative value of these sources,

This quotation shows that quoting the secondary sources is evidence of some learning and processing and hence positive, and the next step is to evaluate these sources, integrating them into support for one's own position. Quotation, though legitimate, is fairly low on the developmental scale if it is not used strategically 'to open the point'.

Thus although regulations can be read as treating documented quotation as an alternative to paraphrase or plagiarism, it is in fact rhetorically undesirable in some disciplines, to be used cautiously in others. Where used inappropriately for the discipline, it is evidence of an early stage of assimilation of disciplinary norms.

\section{Discussion}

Academic intertextuality practices are remarkably complicated. As Swales and Feak (1994) show, each of the range of practices discussed in the introduction has its own place on a scale of legitimacy (Figure 1). 
Figure 1: A Linear model of evaluation of intertextuality (based on Swales and Feak 1994 p 126)

\begin{tabular}{|c|c|c|c|c|c|}
\hline & \multicolumn{2}{|c|}{ Legitimate } & \multicolumn{2}{|c|}{ grey area } & Illegitima \\
\hline $\begin{array}{l}1 \text { Quoting } \\
\text { a paragraph } \\
\text { by placing } \\
\text { it in block } \\
\text { format } \\
\text { with the } \\
\text { source } \\
\text { cited }\end{array}$ & $\begin{array}{l}2 \\
\text { Paraphrasing } \\
\text { a paragraph } \\
\text { by rewriting } \\
\text { with } \\
\text { substantial } \\
\text { changes in } \\
\text { language and } \\
\text { organisation } \\
\text { and examples }\end{array}$ & $\begin{array}{l}3 \text { Composing } \\
\text { a paragraph } \\
\text { by taking } \\
\text { short } \\
\text { standard } \\
\text { phrases from } \\
\text { a number of } \\
\text { sources and } \\
\text { putting them } \\
\text { together with } \\
\text { some words } \\
\text { of your own }\end{array}$ & $\begin{array}{l}4 \text { Cutting and } \\
\text { pasting a } \\
\text { paragraph by } \\
\text { using the } \\
\text { sentences of } \\
\text { the original } \\
\text { but leaving one } \\
\text { or two out, or } \\
\text { by putting one } \\
\text { or two } \\
\text { sentences in a } \\
\text { different order }\end{array}$ & $\begin{array}{l}5 \text { Copying a } \\
\text { paragraph } \\
\text { making only } \\
\text { small } \\
\text { changes, } \\
\text { such as } \\
\text { replacing } \\
\text { few verbs or } \\
\text { adjectives } \\
\text { with } \\
\text { synonyms. } \\
\text { near-copying }\end{array}$ & $\begin{array}{l}6 \text { Copying } \\
\text { a paragraph } \\
\text { as it is } \\
\text { from the } \\
\text { source } \\
\text { without } \\
\text { any } \\
\text { acknow- } \\
\text { ledgement }\end{array}$ \\
\hline
\end{tabular}

However, our interviews showed that a linear view like this can be misleading to students. The first strategy is likely to be very ineffective in most disciplines (Extracts 17, 19, 20), whereas the second (assuming documentation of the intertextuality) is as legitimate and has the potential to be much more effective (Extracts 12,13,14). Another dimension is needed in our conception of academic intertextuality - the dimension of effectiveness or success.

The prototypical good student synthesises sources, adds references, tops off with a well-chosen and referenced quotation, and gets a good grade. This work is legitimate and successful. The prototypical plagiarist copies a whole paper off an obscure site on the Internet (or better still an obscure paper document in the library), doctors it slightly, and gets a good grade. This is wholly illegitimate in terms of the university rules and apparently often wholly successful (Ryan 1998) (except that according to folklore a published paper may only get a mediocre grade when submitted as a student essay).

Legitimate or not, both these prototypes are effective or successful. Let us look at prototypical ways of being unsuccessful. One student finds useful bits in the sources, copies them out without quotation marks or references, and adds a few original words here and there to try to connect the extracts quotations. His essay is illegitimate and fails because the examiner can see that it is copied and there is no synthesis or argumen- 
tation. Another does the same thing with meticulous quotation marks and references, producing a wholly legitimate essay which fails because there is no synthesis or argumentation (cf extract 20 above)

Legitimate or not, both these prototypes are unsuccessful. Legitimacy and success are unrelated. The task set to the student, whether a research student or an undergraduate, is to digest and synthesise the material, or rather to produce a text which digests and synthesises the material, and it is possible to produce a successful text (one which gets a good grade) by legitimate or illegitimate means. It is also possible to produce a text which fails to meet the criteria for success by legitimate or illegitimate means. So we need a two-dimensional view of intertextuality strategies, as in Figure 2:

Figure 2: Some intertextuality practices in relation to intracultural effectiveness and legitimacy

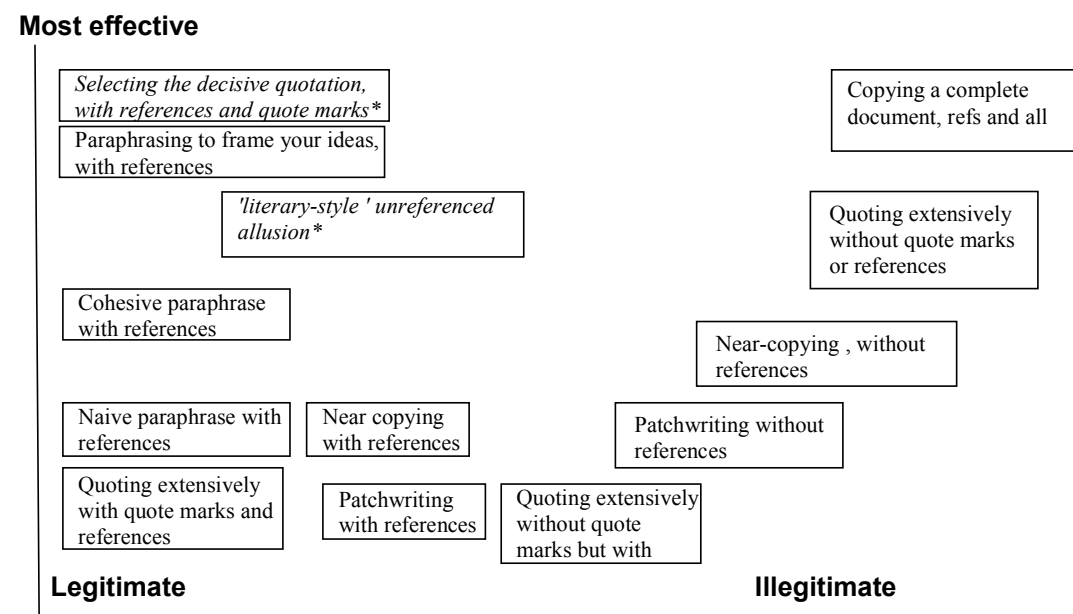

Least effective

*depends on discipline

Figure 2 shows many of the practices discussed above, with the evaluations of them implied by our interviews. We have treated allusion - flouting the conventions - as a practice with considerable effect but dubious legitimacy because it works by identifying the writer as an insider 


\section{4}

on other than purely disciplinary grounds and is not public in the way referenced citation is. Figure 2 shows that in practice the notion of plagiarism in our culture is not black-and-white but quite highly differentiated. It does not focus on the formal rule in the university regulations, but allows for development, and is also very deeply entwined with the whole process of writing a thesis and coming to a personal version of the institutional voice (Extract 6).

Consequently, although the letter of the University law still threatens the transparent plagiarist with dire penalties, one can consider that there is really not much wrong with transparent plagiarism: it is failure to perform the task which is unrewarded like any other failure, such as not having read or understood the textbook. This explains the relaxed attitude shown to it by several supervisors. (Extracts 1,2 and 5). The disciplinary differences that appeared in judgements about copying the precise wording of sources reflects the relationship between the writer's contribution and the words in which it appears. In technology the key findings are numbers and formulae, and valid numbers and formulae are to some extent evidence that previous research has been digested and synthesised, while in the humanities textual formulation and framing are closer to the essence of the findings.

There is also a difference in attitudes to intertextuality and plagiarism according to level of studies. At school, in most cultures, referencing is not emphasised, and indeed intertextuality may not be either; there may be an emphasis on 'one's own thoughts in one's own words'. In undergraduate studies there starts to be a demand for intertextuality and sanctions against plagiarism. There is also a lot of scope for plagiarism at this level; often all the instructor sees is the finished product which may have been produced by any of a variety of strategies, and often the instructor has a large number of papers to mark and does not investigate closely. Most reports of successful plagiarism (Currie, Spack Ryan) come from this level. Our investigation focused on postgraduate studies, and here we see that students are often working so closely with supervisors on drafts or on a series of essays that plagiaristic practices are detected early and viewed as developmental problems rather than crimes. In other words, plagiarism perceived as 'criminal' deception occurs where the focus is on presenting a certain product rather than on going through the correct process. 
There is also a difference in attitudes to intertextuality and plagiarism according to level of studies. At school, in most cultures, referencing is not emphasised, and indeed intertextuality may not be either; there may be an emphasis on 'one's own thoughts in one's own words'. In undergraduate studies there starts to be a demand for intertextuality and sanctions against plagiarism. There is also a lot of scope for plagiarism at this level; often all the instructor sees is the finished product which may have been produced by any of a variety of strategies, and often the instructor has a large number of papers to mark and does not investigate closely. Most reports of successful plagiarism (Currie, Spack Ryan) come from this level. Our investigation focused on postgraduate studies, and here we see that students are often working so closely with supervisors on drafts or on a series of essays that plagiaristic practices are detected early and viewed as developmental problems rather than crimes. In other words, plagiarism perceived as 'criminal' deception occurs where the focus is on presenting a certain product rather than on going through the correct process. There even appears to be a difference between short Masters' theses and PhDs because the interaction with the supervisor is so long and intensive on a $\mathrm{PhD}$ that criminal plagiarism would be hard to carry out.

Separately, there are different attitudes to intertextuality practices according to the stage of development the student has reached with in the university. One supervisor observed that undergraduate lab reports are better with copied sections than generically inappropriate (4.2.2), which implies that the copying is a way to learn the generic requirements, and Extracts 6, 7, 8, and 20, make the same point.

We conclude with some considerations as to the implications for institutions and teachers of a more differentiated view of intertextuality practices.

From the perspective of the institution, novice academic writers, particularly those with limited proficiency in the language they have to write in, have first to learn the importance of referencing. Appropriately referenced intertextuality is open to inspection as to whether conventions of paraphrasing have been followed, so that copying is regarded as evidence of incompetence, lack of critical faculty, etc. rather than criminal intent. In fact, in our view it is often evidence of inadequate linguistic 


\section{6}

proficiency, and as more and more people are forced to study in a language other than their own, one may question how far any other conclusion should be drawn.

From the perspective of the student writing in a foreign language, there is a good chance that copying will be successful, at least in undergraduate courses, if lightly referenced, whereas incomprehensible or naïve attempts at paraphrase may lead to failure (Currie 1998). Hence limited or absent referencing may seem the best strategy. Discovery is relatively infrequent, but universities resort to extreme punishments for the few cases they do prosecute, so the decision as to whether to adopt a plagiarising strategy is finely balanced.

It seems to us that for institutions in which a proportion of students are studying in a language they are not wholly familiar with there is really no alternative to an engagement with the reality of intertextuality and its role in the development of disciplinary discourse. Emphasis has to be laid on referencing and not on paraphrase, so that copying is formally treated as it is actually regarded by many teachers - as a phase linguistically weak writers will have to go through. Emphasis has also to be laid on the process of writing and not merely on evaluation of the product, because product-fixation encourages criminal plagiarism. But this may require more intervention by teachers and more support for student language proficiency, and the economics of higher education are unlikely to make this possible.

Until the nature of tertiary education can be changed in this way, and until supervisors uniformly have less schizophrenic views of student intertextuality, we have no choice but to inform students about the dangers of being accused of plagiarism. An external examiner might apply the letter of the law, and no sophisticated argumentation could rescue the student. At the same time, however, we need to work within the academic community for an understanding that apparent plagiarism, in particular when 'committed' by international students, does not necessarily mean a desire to cheat. We should also, above all, work for a debate which takes into account actual practice and actual learning processes in defining what is acceptable and what must be prosecuted as plagiarism. 


\section{References}

Berkenkotter, C. and T. N. Huckin (1995). Genre Knowledge in Disciplinary Communication. Hillsdale, NJ, Lawrence Erlbaum.

Bloch, J. \& Chi, L. (1995). A comparison of the use of citations in Chinese and English academic discourse. In D. Belcher \& G. Braine (Eds.), Academic writing in a second language: Essays on research and pedagogy (pp. 231-274). Norwood, NJ: Ablex.

Cadman, K. (1997). Thesis writing for international students: a question of identity. English for Specific Purposes 16(1): 3-14.

Campbell, C. (1990). Writing with others' words: using background reading text in academic compositions. In B. Kroll (Ed.) Second language writing: Research insights for the classroom (pp. 211-230). Cambridge: Cambridge University Press.

Currie, P. (1998). Staying out of trouble: apparent plagiarism and academic survival. Journal of Second Language Writing, 7(1), 1-18.

Dong, Y. R. (1996). Learning how to use citations for knowledge transformation: nonnative doctoral students' dissertation writing in science. Research in the Teaching of English 30(4): 428-457.

Greenall, A. J. K. (forthcoming). Towards a socio-cognitive account of flouting and floutbased meaning. Thesis, Norwegian Technical University, Trondheim.

Grice, H.P. (1975) Logic and conversation. In Syntax and Semantics 3: Speech Acts, P. Cole, J. L. Morgan (Ed.), Academic Press, New York, p. 41 - 58

Howard, R. M. (1995a). Plagiarisms, authorships, and the academic death penalty. College English 57 (7), 788-806.

Howard, R. M. (1995b). The Gendered Plagiarist. Paper given at 14th Annual Penn State Conference on Rhetoric and Composition (July 12-15, 1995). University Park, PA,

Leeke, P. and P. Shaw (2000). Learners' independent records of vocabulary. System 28: 1-19.

Leki, I. (1995). Coping strategies of ESL students in writing tasks across the curriculum. TESOL Quarterly, 29, 235-260.

Pecorari, Diane (2001). Plagiarism and international students: how the English-speaking university responds. In Belcher, Diane D. and Hirvela, Alan R. Linking Literacies: Perspectives on L2 Reading-Writing Connections. Ann Arbor: University of Michigan

Pennycook, A. (1996). Borrowing others' words: Text, ownership, memory, and plagiarism. TESOL Quarterly 30 (2), 201-230.

Prior, P. (1994). Response, revision, disciplinarity: a microhistory of a dissertation prospectus in sociology. Written Communication, 11(4), 483-533.

Prior, P. (1995a). Tracing authoritative and internally persuasive discourses: a case study of response, revision, and disciplinary enculturation. Research in the Teaching of English, 29(3), 288-325. 


\section{8}

Prior, P. (1995b). Redefining the task: an ethnographic examination of writing and response in graduate seminars. In D. Belcher \& G. Braine (Eds.), Academic Writing in a Second Language (pp. 47-82). Norwood, NJ.: Ablex.

Richards, K. and J. Skelton (1991). How critical can you get? . Sociocultural Issues in English for Academic Purposes. P. Adams, B. Heaton and P. B. Howarth. London, Macmillan. : 24-40

Ryan, Julie (1998). Student Plagiarism in an on-line world. Prism Online December 1998 $\mathrm{http} / / / \mathrm{www}$. asee.org/prism/december/html/student_plagiarism_in_an_onlin.htm

Scollon, R. (1995). Plagiarism and ideology: Identity in intercultural discourse. Language in Society 24, 1-28.

Scollon, R. (1994). As a matter of fact: The changing ideology of authorship and responsibility in discourse. World Englishes 13, 33-46.

Sherman, J. (1992). Your own thoughts in your own words. ELT Journal, 46, 190-198.

University of Newcastle upon Tyne (no date). Assessment Irregularities. Internal student information document.

Standler, R.B. (2000). Plagiarism in Colleges in USA. Available: http://www.rbs2.com/ plag.htm\#anchor888513 (Dec 2001).

Vertex $(2000,5)$. Flera studenter avstängda efter plagiat och tentafusk. Vertex, Umeå

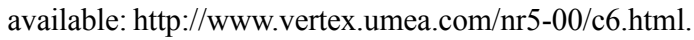

Warner, R. (1999). Plagiarism: An LBOTE Perspective. TESOL in Context 9(2): 24 - 29. 